\section{International collaboration to enhance the fight against HIV/AIDS: report of a consultative meeting between the University of Buea in Cameroon and the Goldfarb School of Nursing in the USA}

\author{
Dickson S. Nsagha, ${ }^{1}$ Neal Rosenburg, ${ }^{2}$ \\ Holly Diesel, ${ }^{2}$ Clement M. Sab, ${ }^{3}$ \\ Donna Taliaferro² \\ 1Department of Public Health and \\ Hygiene, Faculty of Health Sciences, \\ University of Buea, Cameroon; \\ ${ }^{2}$ Goldfarb School of Nursing at Barnes- \\ Jewish College, St. Louis, Missouri, USA, \\ ${ }^{3}$ Department of Nursing, Faculty of \\ Health Sciences, University of Buea, \\ Cameroon
}

\begin{abstract}
HIV/AIDS is a major public health pandemic affecting the development, survival and life of young people both in Cameroon and the USA. Youths are more adaptive to change and less hindered by prejudice than adults. Student-tostudent peer mentoring is a non-formal way for students to learn new life skills and different cross-cultural values. We report on a two-day consultative meeting in 2010 on developing international collaboration for the fight against HIV/AIDS between Cameroonian and USA nursing students. We used adult learning approaches consisting of presentations, discussions, questions and answer sessions, role plays and demonstrations. Deliberations and resolutions from the consultative meeting enabled the Vice-Chancellor of the University of Buea to sign a memorandum of understanding with the Goldfarb School of Nursing in the USA on HIV/AIDS international collaboration paving the way forward for more developmental health projects in this domain.
\end{abstract}

\section{Introduction}

HIV infection fits the profile of a condition that carries a high level of stigmatization. ${ }^{1-3}$ First, people infected with HIV are often blamed for their condition and many people believe HIV could be avoided if individuals made better moral decisions. Second, although HIV is treatable, it is nevertheless a progressive, incurable disease. ${ }^{2,4}$ Third, HIV transmis- sion is poorly understood by some people in the general population, causing them to feel threatened by the mere presence of the disease. Finally, although asymptomatic HIV infection can often be concealed, the symptoms of HIV-related illness cannot. HIV-related symptoms may be considered repulsive, ugly, and disruptive to social interaction. ${ }^{2}$

The discrimination and devaluation of identity associated with HIV-related stigma do not occur naturally. Rather, they are created by individuals and communities who, for the most part, generate the stigma as a response to their own fears. HIV-related stigma manifests itself in various ways. HIV-infected individuals, their loved ones, and even their caregivers are often subjected to rejection by their social circles and communities when they need support the most. They may be forced out of their homes, lose their jobs, or be subjected to violent assault. For these reasons, HIV-related stigma must be recognized and addressed as a life-altering phenomenon., ${ }^{1,5}$

HIV-related stigma has been further divided into instrumental HIV-related stigma, a reflection of the fear and apprehension that are likely to be associated with any deadly and transmissible illness, ${ }^{2}$ external HIV-related stigma, the use of HIV/AIDS to express attitudes toward the social groups or lifestyles perceived to be associated with the disease ${ }^{2}$ and associated HIV-related stigma -stigmatization of people connected to the issue of HIV/AIDS or HIVpositive people. ${ }^{1,5}$

HIV related stigma is expressed around the world in a variety of ways, including ostracism, rejection, and avoidance of people infected with HIV, discrimination against people living with HIV/AIDS (PLWHA), compulsory HIV testing without prior consent or protection of confidentiality, violence against persons who are perceived to have AIDS or to be infected with HIV and quarantine of persons with HIV. HIV related stigma is effectively universal, but its form varies from one country to another, and the specific groups targeted for HIV related stigma vary considerably. Whatever its form, HIV related stigma inflicts suffering on people and interferes with attempts to fight the AIDS pandemic. ${ }^{5}$

Peer-to-peer student mentoring is a very effective teaching and learning mechanism as students tutor and explain in their own language, having a one-on-one contact is an extremely effective learning process, a rare luxury in the normal classroom, students know what they like, it gives increased confidence and a maturity for those mentoring, it gives a chance to share knowledge and enables higher order thinking skills when working in small groups. Student-to-student mentoring focuses on developing linkages on cross-cultural consultations and the management of HIV/AIDS stigma in different settings of Cameroon and
Correspondence: Dickson S. Nsagha, Department of Public Health and Hygiene, Faculty of Health Sciences, University of Buea, P0 Box 63, Buea, Cameroon. Tel. +237.77499429-237.77499429.

E-mail: nsaghads@hotmail.com

Key words: HIV/AIDS, international collaboration, nursing, student-to-student peer mentoring, Cameroon, USA.

Acknowledgements: we appreciate with thanks the support of the Vice-Chancellor of the University of Buea, Professor VPK Titanji and the Deputy Vice-Chancellor in-charge of Research and Cooperation with the Business World, Professor VJ Ngoh, of the University of Buea for the success of the meeting.

Contribution: NDS, epidemiologist, principal investigator, main facilitator of the consultative meeting; NR, nurse, principal investigator on the American side and main facilitator of the meeting; HD, SCM, nurses, co-investigators and main facilitators at the meeting; TD, principal mentor of the project and co-investigator for the collaboration.

Received for publication: 20 April 2011.

Accepted for publication: 18 May 2011.

This work is licensed under a Creative Commons Attribution NonCommercial 3.0 License (CC BYNC 3.0).

CC Copyright D.S. Nsagha et al., 2011

Licensee PAGEPress, Italy

Journal of Public Health in Africa 2011; 2:e22

doi:10.4081/jphia.2011.e22

the USA. HIV /AIDS stigma has been variously reported as factors inhibiting screening and treatment efforts. ${ }^{6}$

These views are studied among a group of trans-cultural students in Cameroon and USA. It is known that varying environmental factors can be associated with the incidence of HIV/AIDS stigma. The USA and Cameroon are likely to have varying ways of managing HIV related stigma. In a previous study, ${ }^{7}$ a significant difference in HIV related stigma was found among Cameroonian and USA nursing students. In this project, a combination of trans-cultural groups of nursing Cameroonian and American students learn and study the problem of HIV/AIDS stigma through peer mentoring using an interactive approach with teachers in the background. Expectantly, factor influence from student's perspective projected through interactive learning among the students should come up with a model for crosscultural interventions in managing HIV-related stigma. Peer learning especially in an interactive process of various backgrounds will produce such a model that covers cross-cultural perspective.

This student mentoring strategy will also enhance the acquisition of knowledge and its transfer to nursing practice. The evaluation of 
the project shall be based on the extent to which acquired peer knowledge is applied in nursing practice, used by HIV infected patients and a significant reduction in HIV-related stigmatisation.

\section{Health care providers and social stigma to HIV/AIDS}

Accessing health care can be a challenge for people who are HIV positive, because the health care system itself is often a source of stigma. Health care professionals, particularly those who infrequently encounter HIV-infected people, can be insensitive to their patients' concerns about stigma. In addition, health care professionals are not always knowledgeable about appropriate procedures for maintaining patient confidentiality. ${ }^{8}$

The literature on care-giving reveals that stigmatization is evident among health care providers. Fear of contagion and fear of death have clear negative effects on health care providers' attitudes toward and treatment of HIV-infected patients. ${ }^{9,10}$

Health care providers also may fear stigmatization themselves because of their work with HIV-infected patients. ${ }^{11}$ Caregivers, whether professionals or volunteers, risk what Goffman called courtesy stigma, in which they are stigmatized as a result of their association with HIV infected persons. That stigma may influence their willingness to work with people with HIV or may make their work more difficult. ${ }^{5}$

\section{History of the collaboration}

The partnership between the University of Buea and the Goldfarb School of Nursing started in 2009, when authorization was given by the Deputy Vice-Chancellor in-charge of Research and Cooperation with the Business World of the University of Buea to Professor Taliaferro and Mr. Rosenburg to administer a questionnaire on HIV related stigma among nursing students. The 2009 survey was not limited to the University of Buea Nursing students but included other institutions like Saint Francis School of Nursing (commonly called Biaka) in Buea, INSAM Douala, and other nursing schools in Nkongsamba and Bonaberri. From September 2-3, 2010, Professors Diesel and Rosenburg visited the University of Buea during which consultative meetings involving principal officers from the Faculty of Health Sciences and Research and Cooperation Division from the Central Administration of the University were held, the results of which is presented in this paper.

\section{Participants at the September 2-3, 2010 consultative meeting in Buea}

The consultative meeting was attended by all Heads of Departments of the Faculty of Health Sciences of the University of Buea including an administrator and cooperation expert, historian and research officer from the Research and Cooperation Division of the University of Buea Central Administration, nursing scientists, community health nurses, a public health epidemiologist, HIV/AIDS nursing experts, registered nurses, a biochemist, a pharmacologist, and an internist. A total of 12 persons participated in the meeting.

\section{Facilitators of the consultative meeting}

Four facilitators organised and participated in the workshop. NDS is the principal investigator on the Cameroonian front who has been working on HIV/AIDS for over 10 years and author of many papers on HIV/AIDS. He is also a lecturer at the Faculty of Health Sciences of the University of Buea in Cameroon where he teaches courses in the Departments of Public Health and Hygiene, Nursing, Medical Laboratory Sciences and the Medicine Programme. NR is an Assistant Professor at the Goldfarb School of Nursing in the USA; has collaborated extensively on HIV/AIDS; he also teaches courses on HIV/AIDS and research methods at the Goldfarb School of Nursing. HD is practising nurse, specializing in obstetrics and HIV/AIDS and she is an Assistant Professor at the Goldfarb School of Nursing in the USA; SCM is a nursing lecturer at the University of Buea and a seasoned nurse specialised in nutrition and community interventions. TD is a Nursing Professor and Associate Dean for Research and Paul McKee endowed Professor at the Goldfarb School of Nursing who has researched on HIV for over two decades.

\section{Consultative meeting with staff from the University of Buea in Cameroon and the Goldfarb School of Nursing in the USA}

A consultation meeting between Cameroonian and American partners came up with the modalities of instituting student peer mentoring into the nursing profession.

Deliberations and resolutions of the Buea consultation meeting between the Goldfarb School of Nursing and the University of Buea were centered on the following collaborative aspects: i) student/teacher exchange visits for teaching and research between the two institutions with student peers transferring HIV and cultural knowledge bi-directionally under the guidance of lecturers. During the first phase, 4 faculty from the USA visited the University of Buea in March 2011 for two weeks with 8 students. The University of Buea shall do the same in 2012. For the University of Buea, this will involve third and fourth year (Level 300 and 400 Nursing students). This is a quasi experimental design comprising of a pre-test, a post test at the end of the peer teaching intervention and a second post test approximately three months later; ii) Dr. Neal Rosenburg will attempt to secure a sabbatical leave to teach courses on HIV and research methods and guest lectures to students of the Faculty of Health Sciences, University of Buea while Dr. Holly Diesel shall do same subsequently the following year to teach courses on HIV/AIDS and Obstetric Nursing. These will be based on funding and approval from the home school; iii) electronic copies of textbooks in medicine, nursing, medical laboratory sciences, public health and hygiene, biomedical and pharmaceutical sciences will be provided to student and staff of the University of Buea. Hard copies of some text books shall also be provided for the library. The lecturers of the Faculty of Health Sciences provided the list of the necessary text books; iv) Funds will be secured for some project activities by the Goldfarb School of Nursing at Barnes Jewish College, USA team; v) a Memorandum of Understanding was signed between the two institutions. This MOU shall be initiated by the University of Buea.

\section{Criteria for selecting nursing stu- dents}

The following selection criteria shall be used to recruit Cameroonian students to be involved in the project:

1. A maximum of 68 Cameroonian students shall be selected comprising of 37 from level 300 and 31 from level 400 . This number shall be matched on a ratio of 1 to 8 with the American cohort (that is, one American student to a maximum of 8 Cameroonian students) for the peer mentoring.

2. A good academic performance in any social sciences or psychosocial nursing disciple. The grade of B plus in any psycho-social disciple shall be the inclusion criteria.

3. The availability of each student for the pretest and the workshop in March 2011 and the post-test interview in May 2011.

The following selection criteria shall be used to recruit American students to be involved in the project:

1. A maximum of 8 American students will be selected following a recruitment process in early fall of 2010 .

2. Students eligible for application will have taken or be enrolled in the HIV elective course as well as the Women's Health/ Childbearing course.

3. Eligibility requirements are a minimum GPA of 3.0 , good standing with the college in all respects including financial standing, and ability to meet all fees associated with travel for the trip in March.

4. Application packets will consist of two letters of recommendation, one of which must be from a GSON faculty, a personal letter of 
intent and a transcript of all course work.

5. Final selection will be based on interviews with the faculty team leading the trip to Cameroon.

\section{Impressions of participants of the consultation meeting}

All Cameroonian participants including Heads of Departments and Heads of Services were very satisfied with the collaboration and they expressed the view that many partners from the West have been visiting the University of Buea for collaborative work but the Goldfarb School of Nursing experience has been very elaborate with a lot of concentration on forming long term relationships. They said the Goldfarb team has been very committed to their ideology of collaboration on HIV/AIDS by respecting their September meeting following the first encounter with the Buea team in March 2009.

\section{Conclusions}

The project will enhance student-to-student peer mentoring skills among Cameroonian and USA nursing students on HIV social stigma, control and management nursing strategies to better fight against this modern plague and the attainment of the health and healthrelated Millennium Development Goals. This will be done through cross-cultural consultations without changing the training curriculum of the two schools.

\section{The way forward after the meeting}

After the September 2010 consultative meeting with the Buea team and faculty management, and reports from the Buea team to the Vice-Chancellor of the University of Buea, a Memorandum of Understanding (MOU) was signed between the Goldfarb School of Nursing and the University of Buea. After the successful consultative meeting, the Vice-Chancellor of the University of Buea addressed congratulatory letters to Professor Donna Taliferro, Associate Dean of Research of Goldfarb and Dr. Nsagha Dickson Shey and Mr. Sab Clement Mume from the University of Buea team. Following these developments, a team of four USA academic staff and eight nursing students and 52 Cameroonian students and three academic staff participated in a Global Capacity Building Train-the-Trainer International Workshop on HIV from March 4-12, 2011 at the University of Buea (this workshop and many other developments after the September 2010 meeting constitute a separate report).

\section{References}

1. Goffman E. Stigma: Notes on the Management of Spoiled Identity. 1963, Simon \& Schuster, Inc., New York, USA.

2. Herek GM, Capitanio JP. AIDS stigma and sexual prejudice. Am Behav Scientist 1999;42:1126-43.

3. Jones EE, Farina A, Hastorf AH, et al. Social Stigma: The Psychology of Marked Relationships. 1984, W.H. Freeman \& Co.,
New York, NY, USA.

4. Stoddard T. Don't call it AIDS: HIV disease is more appropriate. The New York Times, August17, 1994, Sect. A:15.

5. Snyder M, Omoto AM, Crain AL. Punished for their good deeds: stigmatization for AIDS volunteers. Am Behav Scientist 1999;42:1175-92.

6. Wasti SP, Randall J, Simkhada P, van Teijlingen E. In what way do Nepalese cultural factors affect adherence to antiretroviral treatment in Nepal? Health Sci J 2011;5:37-47.

7. Rosenburg N. Taliaferro D., Ercole P., 2011. Cameroon: The State of HIV-Related Stigma among Nursing Students. J Assoc Nurses AIDS Care (in press) 2011.

8. Herek GM, Capitanio JP. Symbolic prejudice or fear of infection? A functional analysis of AIDS-related stigma among heterosexual adults. Basic App Soc Psychol 1998;20:230-41.

9. Gerbert B, Sumser J, Maguire BT. The impact of who you know and where you live on opinions about AIDS and health care. Soc Sci Med 1991;32:677-81.

10. Weinberger M, Conover CJ, Samsa GP, Greenberg SM. Physicians' attitudes and practices regarding treatment of HIVinfected patients. South Med J. 1992;85: 683-6.

11. Durham JD. The changing HIV/AIDS epidemic: emerging psychosocial challenges for nurses. Nurs Clin North Am. 1994;29:918. 